\title{
Co-precipitation synthesis and upconversion luminescence properties of $\mathrm{ZrO}_{2}: \mathrm{Yb}^{3+}-\mathrm{Ho}^{3+}$
}

\author{
JINSHENG LIAO*, SHAOHUA LIU, LILING NIE, SUIJUN LIU and JUNXIANG FU \\ School of Metallurgy and Chemistry Engineering, Jiangxi University of Science and Technology, \\ Ganzhou, Jiangxi 341000, China
}

MS received 24 October 2014; accepted 13 February 2015

\begin{abstract}
ZrO}_{2}: \mathrm{Yb}^{3+}-\mathrm{Ho}^{3+}$ phosphors with different $\mathrm{Yb}^{3+}$ doping concentration have been prepared by coprecipitation method. X-ray diffraction (XRD), scanning electron microscope (SEM) and photoluminescence spectra were used to characterize the properties of $\mathrm{ZrO}_{2}: \mathrm{Yb}^{3+}-\mathrm{Ho}^{3+}$ phosphors. Different phases of $\mathrm{ZrO}_{2}$ can be obtained by changing the concentration of $\mathrm{Yb}^{3+}$. Under the $980 \mathrm{~nm}$ excitation, the sample gives a set of light: strong green $(539 \mathrm{~nm})$, weak red $(670 \mathrm{~nm})$ and near-infrared $(760 \mathrm{~nm})$. The upconversion luminescence is based on two-photon absorption by the energy transfer from the donor $\left(\mathrm{Yb}^{3+}\right)$ to the acceptor $\left(\mathrm{Ho}^{3+}\right)$. All the results indicate that $\mathrm{ZrO}_{2}: \mathrm{Yb}^{3+}-\mathrm{Ho}^{3+}$ phosphors could be a promising biological labelling material.
\end{abstract}

Keywords. $\quad \mathrm{ZrO}_{2}$; phosphor; co-precipitation; upconversion.

\section{Introduction}

Researches of rare-earth-doped upconversion (UC) materials as fluorescent labels, temperature-sensing probes, solid-state lasers and new generation television screens have recently started to be considered ${ }^{1,2}$ due to their enhanced luminescent properties induced by the small size. UC process is the generation of visible or UV light from lower energy radiation (usually near-infrared radiation), through the use of lanthanide, such as $\mathrm{Er}^{3+}, \mathrm{Tm}^{3+}$ and $\mathrm{Ho}^{3+}$, doped into a solid-state host. ${ }^{3}$ The use of $\mathrm{Yb}^{3+}$ as sensitizer of $\mathrm{Ho}^{3+}$ is an option due to efficient energy transfer between $\mathrm{Yb}^{3+}$ and $\mathrm{Ho}^{3+}$ and the existence of commercially available diode lasers operating around $980 \mathrm{~nm}$ suitable for pumping $\mathrm{Yb}^{3+}$ ions. ${ }^{4}$ Recently, oxide nanocrystals as UC hosts have been intensively investigated due to good chemical stability. ${ }^{5}$ Especially, $\mathrm{ZrO}_{2}$ host can be used in a variety of photonics and industrial applications due to low phonon energy $\left(470 \mathrm{~cm}^{-1}\right)$, superior hardness, high refractive index, optical transparency and chemical stability. 6,7

Considerable amount of work has been reported on the mechanical and other physical properties of $\mathrm{ZrO}_{2}: \mathrm{Yb}^{3+}-\mathrm{Ln}^{3+}$ $\left(\mathrm{Ln}^{3+}=\mathrm{Er}^{3+}, \mathrm{Tm}^{3+}\right),{ }^{8,9}$ whereas only few research works have been done on the luminescence properties of $\mathrm{ZrO}_{2}$ : $\mathrm{Yb}^{3+}-\mathrm{Ho}^{3+}$. Solís et $a l^{10}$ and Rosa et $a l^{11}$ have prepared $\mathrm{ZrO}_{2}: \mathrm{Yb}^{3+}-\mathrm{Ho}^{3+}$ by sol-gel method and studied their structural and UC emission properties. Co-precipitation is one of the most promising techniques because air-stable and moisture-stable precursor powders can be prepared on a large scale in water rather than in organic chemicals. However to our knowledge, no paper about $\mathrm{ZrO}_{2}: \mathrm{Yb}^{3+}-\mathrm{Ho}^{3+}$ prepared

\footnotetext{
*Author for correspondence (jsliao1209@126.com)
}

by co-precipitation has been reported. In this work, the UC luminescence properties of the $\mathrm{ZrO}_{2}: \mathrm{Yb}^{3+}-\mathrm{Ho}^{3+}$ nanocrystals as a function of the $\mathrm{Yb}^{3+}$ content are investigated. With the increase of $\mathrm{Yb}^{3+}$ concentration, the samples transit from monoclinic to cubic phase. Explanations for this UC luminescence behaviour are presented and discussed via the variation of excitation power at $980 \mathrm{~nm}$.

\section{Experimental}

The powder samples of $\mathrm{ZrO}_{2}: \mathrm{Yb}^{3+}$ (1-16 mol\%)-Ho ${ }^{3+}$ (fixed $1 \mathrm{~mol} \%$ ) have been synthesized using a homogeneous co-precipitation method. $\mathrm{ZrOCl}_{2} \cdot 8 \mathrm{H}_{2} \mathrm{O}(\mathrm{AR}), \mathrm{Yb}_{2} \mathrm{O}_{3}$ (99.99\%), $\mathrm{Ho}_{2} \mathrm{O}_{3} \cdot 6 \mathrm{H}_{2} \mathrm{O}(99.99 \%)$ and ammonium hydroxide were prepared for the starting materials without further purification. A procedure for the sample synthesis of $\mathrm{ZrO}_{2}: \mathrm{Yb}^{3+}$ $\mathrm{Ho}^{3+}$ is typically described as follows: $\mathrm{Yb}_{2} \mathrm{O}_{3}$ and $\mathrm{Ho}_{2} \mathrm{O}_{3}$ were dissolved in dilute nitric acid under heating. After the $\mathrm{Yb}_{2} \mathrm{O}_{3}$ and $\mathrm{Ho}_{2} \mathrm{O}_{3}$ were completely dissolved, the excess nitrite acid was removed at high temperature. Then deionized water was added to obtain $\mathrm{Yb}\left(\mathrm{NO}_{3}\right)_{3}$ and $\mathrm{Ho}\left(\mathrm{NO}_{3}\right)_{3}$ solutions. Subsequently, certain amount of $\mathrm{ZrOCl}_{2} \cdot 8 \mathrm{H}_{2} \mathrm{O}$, $\mathrm{Yb}\left(\mathrm{NO}_{3}\right)_{3}$ and $\mathrm{Ho}\left(\mathrm{NO}_{3}\right)_{3}$ were dissolved in de-ionized water. The mixture was stirred for $0.5 \mathrm{~h}$ to obtain a homogeneous solution. Then the white precipitate was formed by slowly dropped ammonium hydroxide with magnetic stirring. The precipitate was filtrated and washed twice with de-ionized water. The precipitate was dried at $80^{\circ} \mathrm{C}$ in oven for $10 \mathrm{~h}$. In the end, the precipitate was grinded and annealed at $850^{\circ} \mathrm{C}$ for $3 \mathrm{~h}$ in air to obtain the white phosphor sample. The other phosphors of $\mathrm{ZrO}_{2}: \mathrm{Yb}^{3+}-\mathrm{Ho}^{3+}$ with different $\mathrm{Yb}^{3+}$-doped concentration were synthesized by the same procedure with the corresponding amount of raw materials. 
The samples were characterized by powder X-ray diffraction (XRD) performed on a Panalytical X' Pert diffractometer using $\mathrm{CuKa}_{1}$ radiation $(\lambda=0.154187 \mathrm{~nm})$. The morphology patterns of samples were obtained on a field emission scanning electron microscope (SEM JSM6700F) equipped with an energy-dispersive X-ray spectrum (EDS). The UC luminescence spectra excited with a mode-locked picosecond Ti:Sapphire laser (Tsunami, Spectra Physics) at $980 \mathrm{~nm}$ were detected with PMT detector (R928). Raman spectra were obtained on a Jobin-Yvon HR800 Laser Raman Microscope under $488 \mathrm{~nm}$ laser excitation. All measurements were carried out at room temperature.

\section{Results and discussion}

\subsection{Structure, morphology and composition of $\mathrm{ZrO}_{2}: \mathrm{Yb}^{3+}-\mathrm{Ho}^{3+}$}

The XRD patterns of $\mathrm{ZrO}_{2}: \mathrm{Yb}^{3+}-\mathrm{Ho}^{3+}$ for different concentration of $\mathrm{Yb}^{3+}$ co-doped with $1 \mathrm{~mol} \%$ of $\mathrm{Ho}^{3+}$ in comparison with the standard cards are shown in figure 1. It can be seen clearly from figure 1 that, with the increase of $\mathrm{Yb}^{3+}$ doping concentration, the phase of $\mathrm{ZrO}_{2}: \mathrm{Yb}^{3+}-\mathrm{Ho}^{3+}$ samples convert from the mixed phase to the pure cubic phase. All diffraction peaks in XRD curve of $\mathrm{ZrO}_{2}: 1 \mathrm{~mol} \% \mathrm{Yb}^{3+}$ $1 \mathrm{~mol} \% \mathrm{Ho}^{3+}$ are indexed to mixed phase, namely, in good agreement with the standard data of monoclinic $\mathrm{ZrO}_{2}$ (Joint

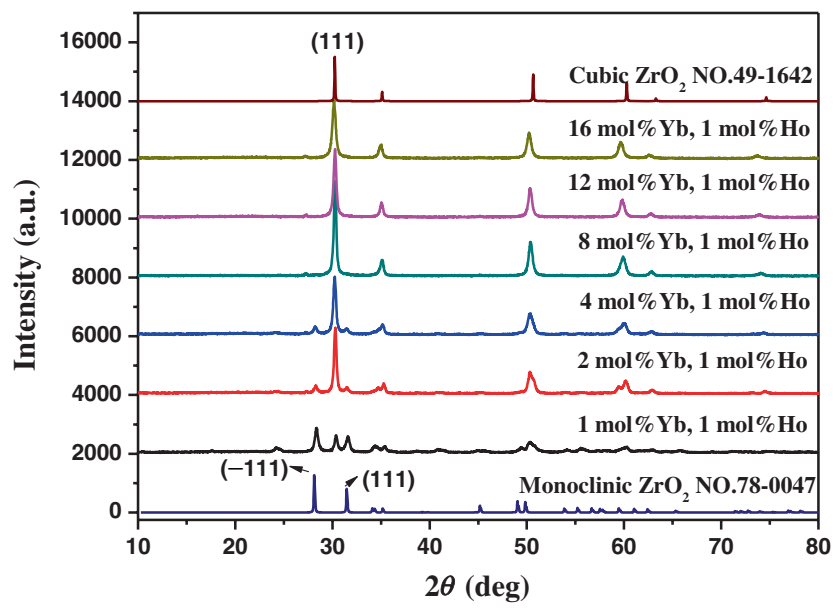

Figure 1. $\mathrm{XRD}$ patterns of $\mathrm{ZrO}_{2}: \mathrm{Yb}^{3+}-\mathrm{Ho}^{3+}$ nanocrystals for different concentrations $(1,2,4,8,12$ and $16 \mathrm{~mol} \%)$ of $\mathrm{Yb}^{3+}$ co-doped with $1 \mathrm{~mol} \%$ of $\mathrm{Ho}^{3+}$.
Committee for Power Diffractions Standards, JCPDS card no. 78-0047) and cubic $\mathrm{ZrO}_{2}$ (JCPDS no. 49-1642). When the $\mathrm{Yb}^{3+}$ content is added to 2 and $4 \mathrm{~mol} \%$, the phase of the phosphor is also a mixture of monoclinic and cubic phase. However, the proportion of the ingredients is different. The fraction of monoclinic phase in the sample should be given by Garvie et al: ${ }^{12}$

$$
C_{\mathrm{m}}=\frac{I_{\mathrm{m}}(-111)+I_{\mathrm{m}}(111)}{I_{\mathrm{m}}(-111)+I_{\mathrm{m}}(111)+I_{\mathrm{c}}(111)} .
$$

And the fraction of cubic phase is calculated by:

$$
C_{\mathrm{c}}=1-C_{\mathrm{m}},
$$

where $\mathrm{m}$ and $\mathrm{c}$ stand for monoclinic and cubic phase of the host and $I$ stands for the integrated intensity of each peak. The calculated results are shown in table 1. From table 1, we can see that the content of cubic phase of the samples become more with the $\mathrm{Yb}^{3+}$ doping concentration increasing. And continued to increase the amount of $\mathrm{Yb}^{3+}$ under the same conditions, the phase of the $\mathrm{ZrO}_{2}: \mathrm{Yb}^{3+}-\mathrm{Ho}^{3+}$ samples converted to the pure cubic phase. This confirms the influence of $\mathrm{Yb}^{3+}$ ion doping concentration on regulating phase.

SEM showed that the morphology of the sample was elliptical spherical about $50 \mathrm{~nm}$ in size and the powder particles are aggregate (see figure $2 \mathrm{a}$ ). EDS reveal that the chemical composition of the sample contained $\mathrm{Zr}, \mathrm{O}, \mathrm{Yb}$ and $\mathrm{Ho}$ (see figure 2b). The results indicated that $\mathrm{Yb}^{3+}$ and $\mathrm{Ho}^{3+}$ have been effectively incorporated into the $\mathrm{ZrO}_{2}$ host lattice, agreeing with the XRD analysis above.

\subsection{Raman spectra}

In order to investigate the phonon frequency of as-obtained $\mathrm{ZrO}_{2}$ samples, Raman spectra were measured. Figure 3 shows the Raman spectra of the $\mathrm{ZrO}_{2}: \mathrm{Yb}^{3+}-\mathrm{Ho}^{3+}$ (the mole ratio $\mathrm{Yb}: \mathrm{Ho}=1: 1$ and 12:1) nanocrystals. For cubic $\mathrm{ZrO}_{2}: 12 \mathrm{~mol} \% \mathrm{Yb}^{3+}-1 \mathrm{~mol} \% \mathrm{Ho}^{3+}$, their Raman bands are lying at 141, 248, 316, 460 and $628 \mathrm{~cm}^{-1}$. These peaks are similar to $\mathrm{Ce}_{1-x} \mathrm{Zr}_{x} \mathrm{O}_{2}(x=0.4-0.7)$ with fluorite cubic phase. ${ }^{13}$ The result indicated that the maximum phonon frequency of cubic $\mathrm{ZrO}_{2}$ is about $628 \mathrm{~cm}^{-1}$. For $\mathrm{ZrO}_{2}: 1 \mathrm{~mol} \% \mathrm{Yb}^{3+}-1 \mathrm{~mol} \% \mathrm{Ho}^{3+}$ of mixed (monoclinic and cubic) phase, the maximum phonon frequency of monoclinic $\mathrm{ZrO}_{2}$ is about $742 \mathrm{~cm}^{-1}$, which is similar to pure $\mathrm{ZrO}_{2}$ with monoclinic phase. ${ }^{14}$ The maximum phonon frequency of tetragonal $\mathrm{ZrO}_{2}$ is about $643 \mathrm{~cm}^{-1} \cdot{ }^{15}$ Compared with the

\begin{tabular}{|c|c|c|c|c|c|}
\hline \multirow[b]{2}{*}{ Sample } & \multirow{2}{*}{$\begin{array}{c}\text { Cubic } \\
I_{\mathrm{c}}(111) \\
\end{array}$} & \multicolumn{2}{|c|}{ Monoclinic } & \multirow{2}{*}{$\begin{array}{l}\text { Content of } \\
\text { cubic }(\%)\end{array}$} & \multirow{2}{*}{$\begin{array}{c}\text { Content of } \\
\text { monoclinic }(\%)\end{array}$} \\
\hline & & $I_{\mathrm{m}}(-111)$ & $I_{\mathrm{m}}(111)$ & & \\
\hline $\mathrm{ZrO}_{2}: \mathrm{Yb}^{3+}-\mathrm{Ho}^{3+}(1: 1)$ & 57 & 100 & 69 & 25.2 & 74.8 \\
\hline $\mathrm{ZrO}_{2}: \mathrm{Yb}^{3+}-\mathrm{Ho}^{3+}(2: 1)$ & 100 & 14 & 11 & 80.0 & 20.0 \\
\hline $\mathrm{ZrO}_{2}: \mathrm{Yb}^{3+}-\mathrm{Ho}^{3+}(4: 1)$ & 100 & 15 & 9 & 80.6 & 19.4 \\
\hline
\end{tabular}

Table 1. The calculated results of content of cubic and monoclinic in $\mathrm{ZrO}_{2}: \mathrm{Yb}^{3+}-\mathrm{Ho}^{3+}$. 

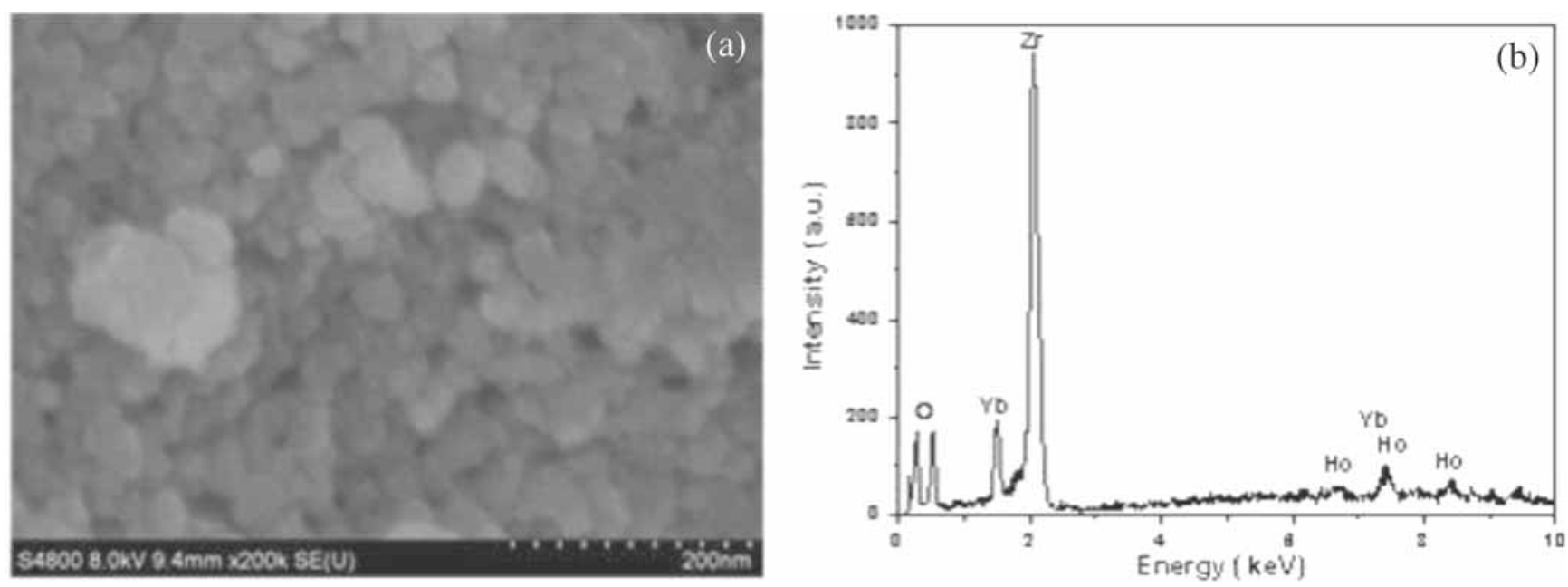

Figure 2. (a) SEM image and (b) EDS pattern of $\mathrm{ZrO}_{2}: \mathrm{Yb}^{3+}-\mathrm{Ho}^{3+}$ nanocrystals.

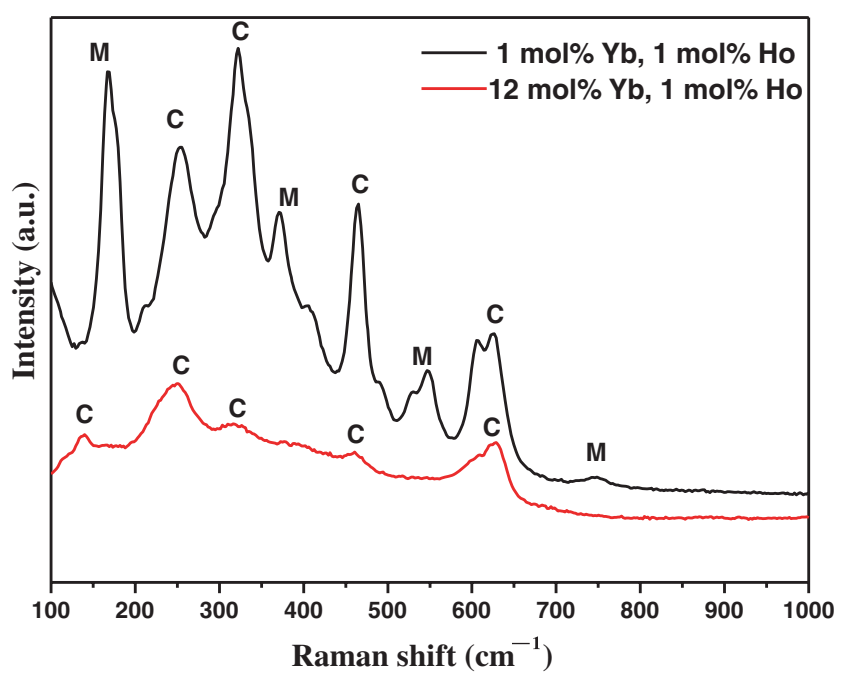

Figure 3. Raman spectra of $\mathrm{ZrO}_{2}: 1 \mathrm{~mol} \% \mathrm{Yb}^{3+}-1 \mathrm{~mol} \% \mathrm{Ho}^{3+}$ with mixed phase of monoclinic (M) and cubic (C) and $\mathrm{ZrO}_{2}: 12 \mathrm{~mol} \% \mathrm{Yb}^{3+}-1 \mathrm{~mol} \% \mathrm{Ho}^{3+}$ with representative cubic phase.

maximum phonon frequency of other oxides $\left(\mathrm{CaMoO}_{4} 815\right.$ $\left.\mathrm{cm}^{-1} ; \mathrm{YPO}_{4} 1091 \mathrm{~cm}^{-1}\right),{ }^{16,17}$ the maximum phonon frequency of cubic $\mathrm{ZrO}_{2}$ host $\left(628 \mathrm{~cm}^{-1}\right)$ is relatively low. Generally, the low phonon frequency of host lattice may lead to strong UC emission. Therefore, cubic $\mathrm{ZrO}_{2}$ is selected as UC host materials.

\subsection{UC luminescence properties}

Figure 4 shows the UC emission spectra of the $\mathrm{ZrO}_{2}: \mathrm{Yb}^{3+}$ $\mathrm{Ho}^{3+}$ nanocrystals with the different $\mathrm{Yb}^{3+}$ doping concentration and the fixed $1 \mathrm{~mol} \%$ of $\mathrm{Ho}^{3+}$ after excitation at $980 \mathrm{~nm}$. For all the phosphors, there were three emission bands centred at about 539.0, 670.5 and $759.5 \mathrm{~nm}$, which were assigned to ${ }^{5} \mathrm{~S}_{2} /{ }^{5} \mathrm{~F}_{4}$ to ${ }^{5} \mathrm{I}_{8},{ }^{5} \mathrm{~F}_{5}$ to ${ }^{5} \mathrm{I}_{8}$ and $\left({ }^{5} \mathrm{~S}_{2} /{ }^{5} \mathrm{~F}_{4}\right)$ to ${ }^{5} \mathrm{I}_{7}$ transitions, respectively. Among them, the peak located

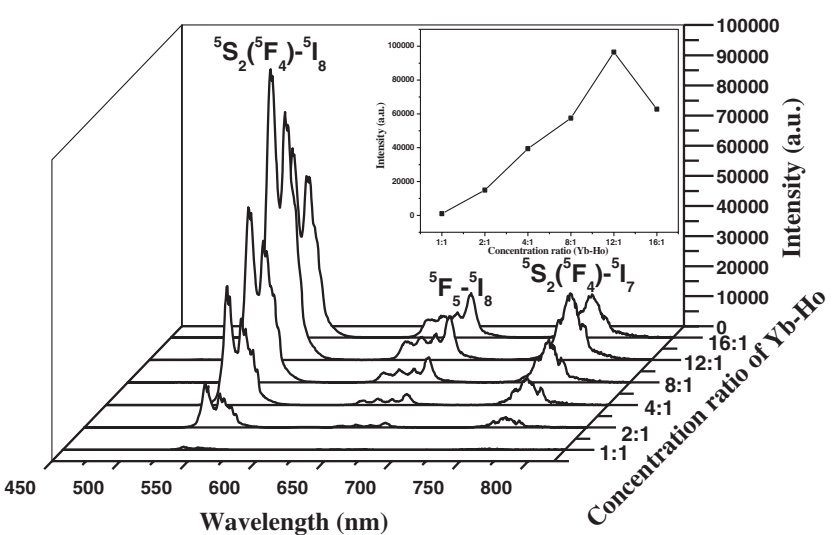

Figure 4. Emission spectra of $\mathrm{ZrO}_{2}: \mathrm{Yb}^{3+}-\mathrm{Ho}^{3+}$ phosphors for different $\mathrm{Yb}^{3+}$ doping.

at $539 \mathrm{~nm}$ is the most intense one. What is more, we can see from figure 4 and the inset that, the peaks of the emission spectra of samples roughly keep the similar shape, but the intensity is different. The intensity of emission spectra is increased with the $\mathrm{Yb}^{3+}$ doping concentration increasing until $12 \mathrm{~mol} \%$. When the $\mathrm{Yb}^{3+}$ doping concentration is higher above 12 at.\%, the luminescence intensity reduces contrarily owing to the concentration quenching. ${ }^{18}$ So we concluded the optimum doping concentration of $\mathrm{Yb}^{3+}$ to be about $12 \mathrm{~mol} \%$.

To explore the relation between the UC luminescence and crystal phase, we analyse the emission spectra of $\mathrm{ZrO}_{2}:(1,2$, $12 \mathrm{~mol} \%$ ) of $\mathrm{Yb}^{3+}-1 \mathrm{~mol} \% \mathrm{Ho}^{3+}$, which stand for typically mixture and pure cubic phase, respectively (figure 5). From figure 5, it can be seen that the emission peaks at 558 and $561 \mathrm{~nm}$ are disappeared when the phase of $\mathrm{ZrO}_{2}: \mathrm{Yb}^{3+}-\mathrm{Ho}^{3+}$ converted from mixture phase to pure cubic. Here, we can definitely say, $\mathrm{Yb}^{3+}$ doping concentration has played an important role in the generation of new UC emission band. A similar phenomenon was observed in $\mathrm{Yb}^{3+}$ and $\mathrm{Tm}^{3+}$ co-doped $\mathrm{ZrO}_{2}$. 


\subsection{UC luminescence mechanism}

It is known that the UC intensity $(I)$ depends on the excitation power $(P)$ according to the power law: $I \approx P^{n},{ }^{19}$ where the number of pumping photons $(n)$ required to excite ions from the ground state to the emitting state can be determined from the slope of the photoluminescence intensity $v s$. the laser excitation power in a log-log plot. The change points of the fluorescence intensity of each band for $\mathrm{ZrO}_{2}:(12$ $\mathrm{mol} \%) \mathrm{Yb}^{3+}-(1 \mathrm{~mol} \%) \mathrm{Ho}^{3+} v$. the logarithm of pump power ( $\log [$ pump power]) and the fitting results are shown in figure 6. From figure 6, it can be seen that the $n$ values corresponding to the behaviours of the green, red and NIR emission are $1.82,1.77$ and 1.55 , respectively, which indicate the presence of a two-photon absorption mechanism in the UC emission.

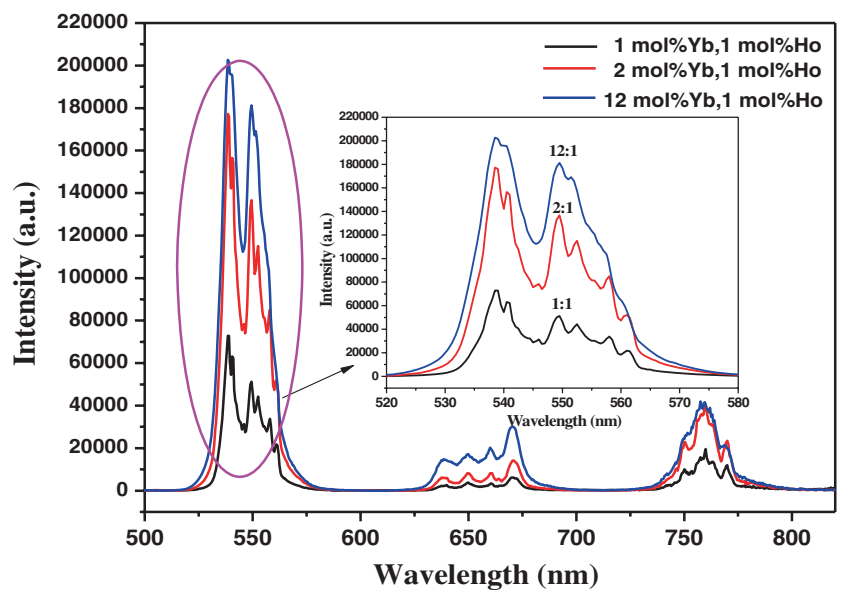

Figure 5. Emission spectra of typical phase pumped by the same power $(1.2 \mathrm{~W})$.

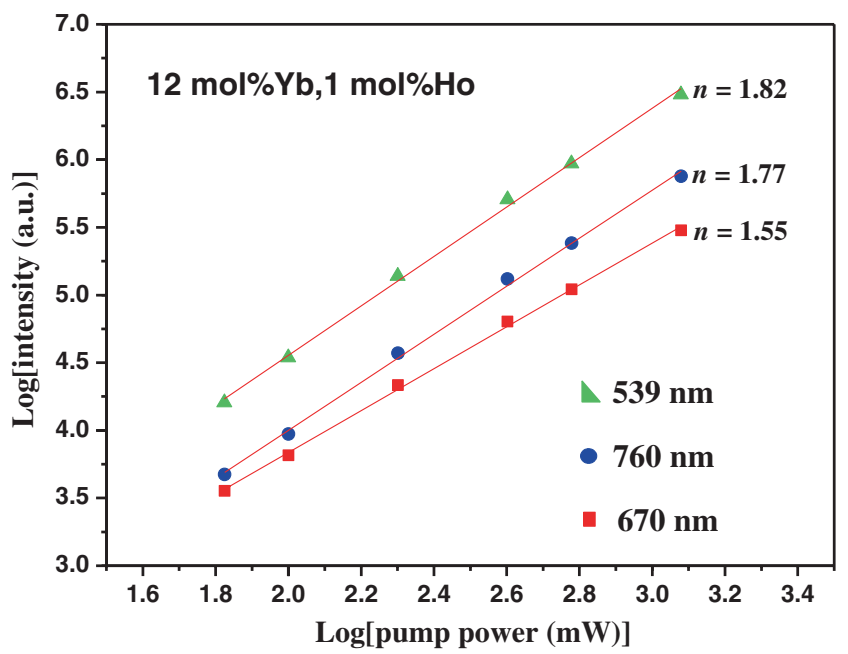

Figure 6. Dependence of the upconverted fluorescence intensity on excitation power under $980 \mathrm{~nm}$ excitation for $\mathrm{ZrO}_{2}:(12$ $\mathrm{mol} \%) \mathrm{Yb}^{3+}-(1 \mathrm{~mol} \%) \mathrm{Ho}^{3+}$.
The generation of the emission channels from the $\mathrm{ZrO}_{2}: \mathrm{Yb}^{3+}-\mathrm{Ho}^{3+}$ system is well explained with the help of the energy level diagrams shown in figure 7. At first, $\mathrm{Ho}^{3+}$ is excited from the ground state $\left({ }^{5} \mathrm{I}_{8}\right.$ level) to the excited state $\left({ }^{5} \mathrm{I}_{6}\right.$ level) via the energy transfer from the excited level ${ }^{2} \mathrm{~F}_{5 / 2}$ of $\mathrm{Yb}^{3+}$. The process can be simply expressed as:

$$
\begin{aligned}
& { }^{2} \mathrm{~F}_{7 / 2}\left(\mathrm{Yb}^{3+}\right)+\mathrm{h} v \rightarrow{ }^{2} \mathrm{~F}_{5 / 2}\left(\mathrm{Yb}^{3+}\right) . \\
& { }^{2} \mathrm{~F}_{5 / 2}\left(\mathrm{Yb}^{3+}\right)+{ }^{5} \mathrm{I}_{8}\left(\mathrm{Ho}^{3+}\right) \rightarrow{ }^{2} \mathrm{~F}_{7 / 2}\left(\mathrm{Yb}^{3+}\right)+{ }^{5} \mathrm{I}_{6}\left(\mathrm{Ho}^{3+}\right) .
\end{aligned}
$$

As soon as the ${ }^{5} I_{6}$ level gets populated, two different ways of electronic depopulation occur. The first way is that part of
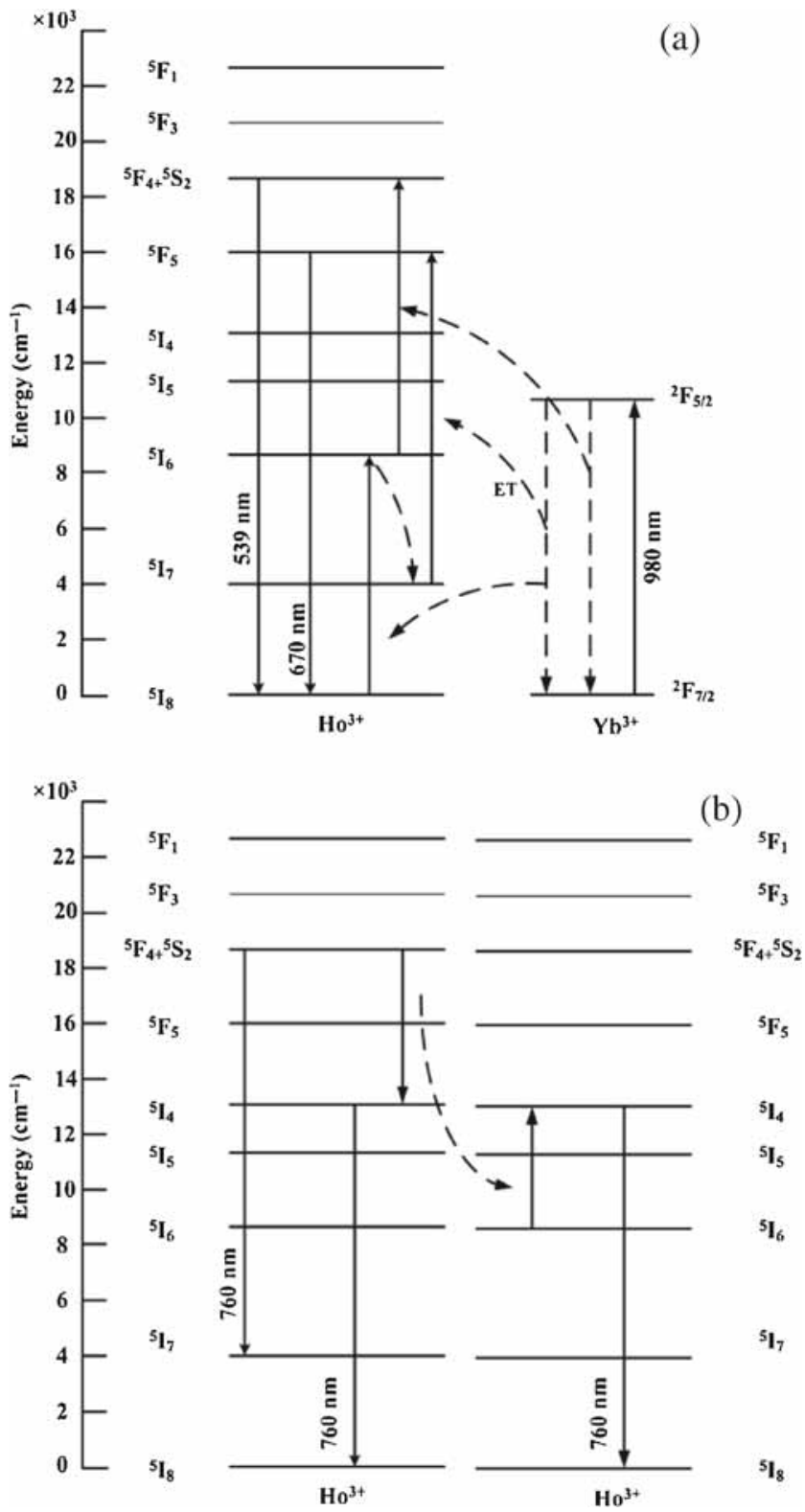

Figure 7. Energy level diagrams for the proposed UPC mechanism: (a) energy transfer diagram of $\mathrm{Yb}^{3+}$ to $\mathrm{Ho}^{3+}$ and (b) cross-relation process among $\mathrm{Ho}^{3+}$ and $\mathrm{Ho}^{3+}$ ions. 
$\mathrm{Ho}^{3+}$ relaxes to the ${ }^{5} \mathrm{I}_{7}$ level via non-radiative mechanism. The ${ }^{5} \mathrm{I}_{7}$ excited ions usually can accept the energy transfer from $\mathrm{Yb}^{3+}$ located at excited state and transit to ${ }^{5} \mathrm{~F}_{5}$ level and from there relaxes to the ground state, producing red emission band centred at $671 \mathrm{~nm}$. The mechanism can described as:

$$
\begin{aligned}
{ }^{5} \mathrm{I}_{7}\left(\mathrm{Ho}^{3+}\right) & +{ }^{2} \mathrm{~F}_{5 / 2}\left(\mathrm{Yb}^{3+}\right) \rightarrow\left({ }^{5} \mathrm{~F}_{5}\right)\left(\mathrm{Ho}^{3+}\right) \\
& +\left({ }^{2} \mathrm{~F}_{7 / 2}\right)\left(\mathrm{Yb}^{3+}\right) .
\end{aligned}
$$

The second way is that part of the ${ }^{5} \mathrm{I}_{6}$ excited ions accept directly energy transfer from $\mathrm{Yb}^{3+}$ located at excited state and transit to ${ }^{5} \mathrm{~S}_{2} /{ }^{5} \mathrm{~F}_{4}$ level, it means:

$$
\begin{aligned}
{ }^{5} \mathrm{I}_{6}\left(\mathrm{Ho}^{3+}\right) & +{ }^{2} \mathrm{~F}_{5 / 2}\left(\mathrm{Yb}^{3+}\right) \rightarrow\left({ }^{5} \mathrm{~F}_{4}+{ }^{5} \mathrm{~S}_{2}\right)\left(\mathrm{Ho}^{3+}\right) \\
& +\left({ }^{2} \mathrm{~F}_{7 / 2}\right)\left(\mathrm{Yb}^{3+}\right) .
\end{aligned}
$$

The $\mathrm{Ho}^{3+}$ located at ${ }^{5} \mathrm{~S}_{2} /{ }^{5} \mathrm{~F}_{4}$ level transit to the ${ }^{5} \mathrm{I}_{8}$ level, producing green emission band centred at $540 \mathrm{~nm}$.

In general, ${ }^{5} \mathrm{I}_{6}$ level lifetime is $5 \mathrm{~ms}$ order of magnitude. ${ }^{20}$ $\mathrm{Ho}^{3+}$ located at this level has a greater likelihood to continue absorbing energy, i.e., more conductive to realize ${ }^{5} \mathrm{~S}_{2} /{ }^{5} \mathrm{~F}_{4}$ level. So we observed in the emission spectra that the emission intensity of green emission is more intense than that of red emission.

From the aspects of energy matching, $\mathrm{Ho}^{3+}$ ions have two transition ways to emit NIR light, shown in figure $7 \mathrm{~b}$. One way is that $\mathrm{Ho}^{3+}$ located at ${ }^{5} \mathrm{~S}_{2} /{ }^{5} \mathrm{~F}_{4}$ level transit to ${ }^{5} \mathrm{I}_{7}$ metastable level, and at the same time $\mathrm{Ho}^{3+}$ emitted NIR emission centred at $761 \mathrm{~nm}$. The second way is ${ }^{5} \mathrm{I}_{4} \rightarrow{ }^{5} \mathrm{I}_{8}$, namely, ${ }^{5} \mathrm{I}_{6}$ level and ${ }^{5} \mathrm{~S}_{2} /{ }^{5} \mathrm{~F}_{4}$ level undergo cross-relaxation to realize ${ }^{5} \mathrm{I}_{4}$ level. The process is explained as:

$$
{ }^{5} \mathrm{I}_{6}\left(\mathrm{Ho}^{3+}\right)+\left({ }^{5} \mathrm{~S}_{2} /{ }^{5} \mathrm{~F}_{4}\right)\left(\mathrm{Ho}^{3+}\right) \rightarrow{ }^{5} \mathrm{I}_{4}\left(\mathrm{Ho}^{3+}\right)+{ }^{5} \mathrm{I}_{4}\left(\mathrm{Ho}^{3+}\right) .
$$

The $\mathrm{Ho}^{3+}$ located at ${ }^{5} \mathrm{I}_{4}$ level transit to the ground state $\left({ }^{5} \mathrm{I}_{8}\right.$ level) producing NIR light about $761 \mathrm{~nm}$.

\section{Conclusion}

In summary, the $\mathrm{ZrO}_{2}: \mathrm{Yb}^{3+}-\mathrm{Ho}^{3+}$ phosphors with different $\mathrm{Yb}^{3+}$ doping concentrations have been synthesized by coprecipitation method. XRD patterns were shown that when the concentration of $\mathrm{Yb}^{3+}$ were 1,2 and $4 \mathrm{~mol} \%$ in the case of the fixed $1 \mathrm{~mol} \%$ of $\mathrm{Ho}^{3+}$, the samples were a mixture of monocline and cubic phase. Continued to increase $\mathrm{Yb}^{3+}$ concentration, the host was stable to cubic phase. We have also confirmed that the emission peaks at 558 and $561 \mathrm{~nm}$ were disappeared when the phase of $\mathrm{ZrO}_{2}: \mathrm{Yb}^{3+}-\mathrm{Ho}^{3+}$ converted from mixture phase to pure cubic. The values of pumping photons $(n)$ indicated that two excitation photons are involved in the UC process. In conclusion, concentration of $\mathrm{Yb}^{3+}$ ions has played a major role in the regulation phase and upconverted emission in $\mathrm{Yb}^{3+}-\mathrm{Ho}^{3+}$ co-doped $\mathrm{ZrO}_{2}$ nanocrystals.

\section{Acknowledgements}

This work was financially supported by the National Natural Science Foundation of China (no. 51162012) and Natural Science Foundation of Jiangxi Province (no. 20142BAB203004). This work was also supported by the Projects under Scientific and Technological planning of the education office, Jiangxi Province (GCJ2011-243), domestic visiting scholar of Jiangxi provincial higher education institution, Jiangxi Province Training Programs of Innovation and Entrepreneurship for Undergraduates (201310407028), the Science Program of the Education Office, Jiangxi Province (no. GJJ14410), and the school subjects of Jiangxi University of Science and Technology (JXXJ11021 and JXXJ12023). We acknowledge Prof Chunhua Yan (College of Chemistry and Molecular Engineering, Peking University) for great help on characterization of Raman spectra.

\section{References}

1. Chen G Y, Zhang Y G, Somesfalean G, Zhan Z G, Sun Q and Wang F P 2006 Appl. Phys. Lett. 89163105

2. Singh B P, Parchur A K, Ningthoujam R S, Ramakrishna P V, Singh S, Singh P, Rai S B and Maalej R 2014 Phys. Chem. Chem. Phys. 1622665

3. Auzel F 2004 Chem. Rev. 104139

4. Jambunathan V, Mateos X, Pujol M C, Carvajal J J, Aguiló M and Díaz F 2010 Phys. Procedia 8162

5. Liu M, Wang S W, Tang D Y, Chen L D and Ma J 2009 J. Rare Earth 2766

6. Rosa E De la, Diaz-Torres L A, Salas P and Rodríguez R A 2005 Opt. Mater. 271320

7. Noh H M, Yang H K, Moon B K, Choi B C, Jeong J H, Choi H and Kim J H 2013 J. Nanosci. Nanotechnol. 134006

8. Liu L, Wang Y X, Zhang X R, Yang K, Bai Y F, Huang C H and Song Y L 2011 Opt. Commun. 2841876

9. Patra A, Saha S, Alencar M A R C, Rakov N and Maciel G S 2005 Chem. Phys. Lett. 407477

10. Solís D, Rosa E De la, Salas P and Angeles-Chávez C 2009 J. Phys. D: Appl. Phys. 42235105

11. Rosa E De la, Salas P, Desirena H, Angeles C and Rodríguez R A 2005 Appl. Phys. Lett. 87241912

12. Garvie R C and Nicholson P S 1972 J. Am. Ceram. Soc. 55303

13. Yuan Q, Liu Q, Song W G, Feng W, Pu W L, Sun L D, Zhang Y W and Yan C H 2007 J. Am. Chem. Soc. 1296698

14. Konioyis C G and Orkoula M 1994 J. Mater. Sci. 295316

15. Shi L, Tin K and Wong N 1999 J. Mater. Sci. 343367

16. Singh B P, Parchur A K, Ningthoujam R S, Ansari A A, Singh P and Rai S B 2014 Dalton Trans. 434770

17. Prasad A I, Parchur A K, Juluri R R, Jadhav N, Pandey B N, Ningthoujam R S and Vatsa R K 2013 Dalton Trans. 424885

18. Patra A 2004 Chem. Phys. Lett. 38735

19. Glaspell G, Anderson J, Wilkins J R and El-Shall M S 2008 J. Phys. Chem. C 11211527

20. Zhang X, Liu X R, Jouart J P and Mary G 1997 Chin. J. Lumin. 18295 